\title{
A Brief Introduction to the Use of Stated-Choice Methods to Measure Preferences for Treatment Benefits and Risks
}

F. Reed Johnson, A. Brett Hauber, and Christine M. Poulos

September 2009 
About the Authors

F. Reed Johnson, PhD, is a Senior

Fellow and principal economist in RTI

Health Solutions

A. Brett Hauber, PhD, is a senior economist and global head of Health Preference Assessment for RTI Health Solutions.

Christine M. Poulos, PhD, is a senior economist in Health Preference Assessment at RTI Health Solutions.
RTI Press publication RR-0009-0909

This PDF document was made available from www.rti.org as a public service of RTI International. More information about RTI Press can be found at http://www.rti.org/rtipress.

RTI International is an independent, nonprofit research organization dedicated to improving the human condition by turning knowledge into practice. The RTI Press mission is to disseminate information about RTI research, analytic tools, and technical expertise to a national and international audience. RTI Press publications are peer-reviewed by at least two independent substantive experts and one or more Press editor.

\section{Suggested Citation}

Johnson, F.R., Hauber, A.B., and Poulos, C.M. (2009). A Brief Introduction to the Use of Stated-Choice Methods to Measure Preferences for Treatment Benefits and Risks. RTI Press publication No. RR-0009-0909. Research Triangle Park, NC: RTI International. Retrieved [date] from http://www.rti.org/rtipress.
This publication is part of the RTI Press Research Report series.

RTI International

3040 Cornwallis Road

PO Box 12194

Research Triangle Park, NC

27709-2194 USA

Tel: $\quad+1.919 .541 .6000$

Fax: $\quad+1.919 .541 .5985$

E-mail: rtipress@rti.org

Web site: www.rti.org
(C)2009 Research Triangle Institute. RTI International is a trade name of Research Triangle Institute.

All rights reserved. Please note that this document is copyrighted and credit must be provided to the authors and source of the document when you quote from it. You must not sell the document or make a profit from reproducing it.

doi:10.3768/rtipress.2009.rr.0009.0909

www.rti.org/rtipress 


\title{
A Brief Introduction to the Use of Stated- Choice Methods to Measure Preferences for Treatment Benefits and Risks
}

\author{
F. Reed Johnson, A. Brett Hauber, and \\ Christine M. Poulos
}

Contents

Introduction

2

Quantifying Preferences

Requirements for a Valid Benefit-Risk Stated-Choice

Study

Treatment Definitions

Alternative Stated-Choice

Formats

Experimental Design

A Numerical Example

Using Stated Preferences to Inform Decisions Involving Benefit-Risk Tradeoffs

\begin{abstract}
Regulatory decisions to approve, restrict development, or halt the marketing of new pharmaceuticals require evaluating the balance between benefits and risks, given the available evidence at a point in time. In response to concerns about how such decisions are reached, there is increasing interest in using patients' perceptions of the benefits of treatment features and their tolerance for possible risks to help inform regulatory decisions. Stated-choice methods, which measure stated preferences and are sometimes called discrete-choice experiments or conjoint analysis, are often the most valid and reliable techniques available for quantifying patient preferences because data on actual choices are limited. This introduction discusses how to adapt and apply stated-choice methods to quantitative benefit-risk analysis. We outline the conceptual framework for measuring patient preferences and the requirements for developing and administering a valid survey instrument. We also provide a numerical example illustrating how stated-choice data can be used to quantify benefit-risk tradeoff preferences. Finally, we discuss some limitations and practical considerations involving its use for regulatory and clinical decision making.
\end{abstract}




\section{Introduction}

Several recent and well-publicized events involving the withdrawal of drugs from the U.S. market have dramatized the problem of balancing the benefits and risks of interventions. In all these cases, interventions offering potentially significant therapeutic benefits were found to carry risks of serious, possibly lifethreatening adverse events. A decision regarding the need to halt the development or marketing of such therapies implies an evaluation of the relative benefits and risks given the available evidence at a point in time. The Institute of Medicine (IOM) noted recently that "in both the pre-approval and the post-marketing setting, the risk-benefit analysis that currently goes into FDA decisions appears to be ad hoc, informal, and qualitative" (Institute of Medicine, 2006). Partly in response to such criticisms, the U.S. Congress included a provision in the recent Food and Drug Administration Amendments Act of 2007 requiring FDA to develop and implement a plan for evaluating the benefits and risks of new pharmaceuticals and for communicating this information to patients and physicians (H.R. 3580 [Public Law 110-85] \$904).

Benefit-risk evaluations are sometimes informed by advisory bodies of scientists and clinicians, although balancing benefits and risks involves making social judgments for which clinical scientists have no special expertise. Decisions are occasionally influenced by patients, the ultimate stakeholders in the drug review and approval process. Patients' values and tolerance for risk are presented to advisory panels and policy makers either directly or through advocacy organizations; however, such anecdotal testimony does not provide systematic evidence of the willingness of well-informed patients to accept expected risks to achieve the therapeutic benefits of these products. Furthermore, it is unclear whether those who advocate for less restrictive or more restrictive access to medications are representative of the population for whom the medication is indicated.

Understanding how patients perceive the benefits of treatment features and their tolerance for possible risks requires a valid and reliable measurement method. Stated-choice (SC) methods, sometimes called discrete-choice experiments or conjoint analysis, are the most valid and reliable techniques available for quantifying patient preferences. Two such studies were recently included in reapproval and approval submissions to FDA advisory committees (Johnson, Özdemir, Mansfield, Hass, Miller, \& Siegel, 2007; Johnson, Van Houtven, Özdemir, Hass, White, \& Francis, 2009). One submission was for reapproval of a product that was withdrawn from the market because of serious safety problems, and the other submission was for approval of the same product for a different indication. In both cases, the FDA approved the use of the product based in part on consideration of the patient preferences for benefits and risks.

This paper provides an overview of using SC methods to quantify benefit-risk tradeoffs for those who are familiar with benefit-risk assessments but not familiar with SC methods. First, we explain how SC data on preferences for treatment attributes can be use to examine patients' willingness to accept the risks of side effects in exchange for improvements in treatment efficacy. Then we explain some key components of an SC study, provide a numerical example, and conclude with a discussion of consideration in using SC data in benefit-risk assessments.

\section{Quantifying Preferences}

Ideally, we would infer patients' preferences from observing real health care decisions. Unfortunately, such data are generally nonexistent for the domains of interest or actual choices are so constrained by institutional, informational, and financial factors that observed choices are a poor indicator of patient preferences. SC methods, which involve evaluation of constructed alternatives in a controlled experiment, may be a far more valid source of data than actual decisions, when they are available.

SC methods recognize that products have value because of their characteristics or attributes. People have preferences for each attribute and are willing to accept tradeoffs among different attributes. SC analysis examines these tradeoffs to assess the weights people assign to various treatment attributes. Analysts have used SC to quantify preferences and willingness 
to pay for a variety of market and nonmarket goods and services. In addition to a long history of market research applications, researchers have more recently adapted these techniques to evaluate environmental policies, public health interventions, and pharmaceutical treatments (Brown, Finkelstein, Brown, Buchner, \& Johnson, 2009; Bryan, Buxton, Sheldon, \& Grant, 1998; Hauber, Mohamed, Johnson, Meddis, Wagner, \& O’Dowd, 2009; Johnson \& Desvousges, 1997; Johnson, Banzhaf, \& Desvousges, 2000; Johnson, Desvousges, Ruby, Stieb, \& De Civita, 1998; Johnson, Manjunath, Mansfield, Clayton, Hoerger, \& Zhang, 2006; Johnson et al., 2009; Mansfield, Johnson, \& Van Houtven, 2006; Mansfield, Phaneuf, Johnson, Yang, \& Beach, 2008; Marshall et al., 2009; Roe, Irwin, \& Morrow-Jones, 2004; Ryan \& Hughes, 1997; Viscusi, Magat, \& Huber, 1991; Wittink \& Cattin, 1989; Yoo, Kwak, \& Lee, 2008).

An important advantage of SC data on benefit-risk tradeoffs is that they can quantify patients' tolerance for risks relative to given levels of benefit. Such data identify the benefit-risk tradeoff curve, as illustrated in Figure 1. For a specified improvement in treatment effectiveness ( $\Delta$ effectiveness), maximum acceptable risk (MAR) is the highest level of risk patients would tolerate in return for the benefits offered by the treatment. If the actual risk exposure is less than MAR, then patients experience a positive net benefit from having access to the treatment, all else equal.

\section{Figure 1. Benefit-risk tradeoff curve and maximum acceptable risk}

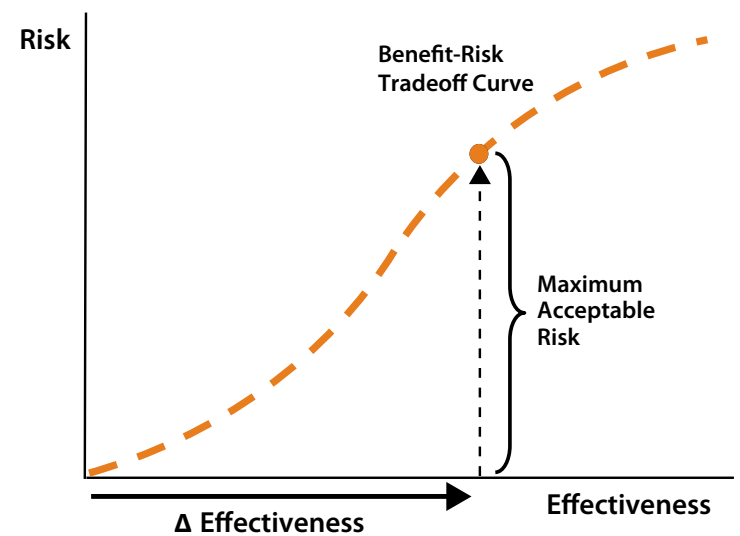

Quantitative estimates of MAR can provide useful information for several areas of health care decision making.

- Development strategies for new pharmaceuticals. If the SC study is undertaken early in the development process, researchers can identify the relative importance that consumers place on product benefits relative to possible risks. The ability to compare benefits and risks directly can lead to better-informed product-development decisions in cases where early data indicate the possibility of an adverse event.

- Regulatory approval. FDA is committed to better quantification of benefits and risks and transparent methods for comparing benefits and risks. FDA regulators have expressed interest in systematically quantifying the anecdotal evidence patients and patient advocacy groups currently provide for product evaluations.

- Risk management. Risk management professionals often must weigh the potential risks of medical interventions to a small number of patients against the potential benefits of the same interventions to a large number of patients. In addition, interventions designed to minimize the risk to patients require understanding behavior that can lead to adverse events. Prescription drug off-label use and nonadherence can occur when there are systematic differences between physicians' and patients' risk tolerance, and regulators' explicit or implicit judgments regarding acceptable risks. SC methods can quantify such differences among various stakeholder groups and help inform effective riskmanagement programs. 


\section{Requirements for a Valid Benefit-Risk Stated-Choice Study}

Implementing a valid and reliable benefit-risk SC study requires accurate treatment definition (attributes and levels), ${ }^{1}$ attention to format selection (ratings, rankings, or choice), efficient experimental design, and careful statistical analysis. The remainder of this document considers each of these study requirements, except statistical analysis, which is beyond the scope of this paper. Readers interested in learning more about SC methods in general and analysis in particular may refer to Hensher, Rose, \& Greene (2005).

\section{Treatment Definitions}

Measuring stated preferences for medical interventions requires a systematic framework to characterize relevant treatments. Demand for such interventions arises directly from preferences for treatment attributes and indirectly from preferences for the health states realized by their use. Thus, attributes and levels must incorporate the most important health outcomes and treatment attributes associated with medical treatments.

While many pharmaceuticals and medical devices have demonstrated clinical value in alleviating symptoms of disease, such benefits are often accompanied by risks of adverse events. These undesirable outcomes can range from mild symptoms such as transitory drowsiness to potentially lifethreatening conditions. Tolerance for adverse-event risks may vary among patients and between patients and physicians. Thus including such risks is important in situations where therapeutic decisions require determining what level of risk is acceptable for a particular patient or group of patients.

Once identified, outcomes associated with treatments must be defined in sufficient detail such that subjects can distinguish between them. In addition, these outcome definitions must be consistent with the ways that people think about their health. For instance, people often do not think of their health in terms of

\footnotetext{
An attribute is a qualitative characteristic of the treatment, while a level is one of several values the attribute may have. Color and price are attributes. Blue and \$25 are levels.
}

clinical outcome measures. Rather, they may consider how the severity of symptoms associated with clinical outcomes limits or affects physical, social, and emotional functioning. It is the task of survey developers to determine how subjects think about health outcomes for the intervention of interest and to identify salient attributes and levels. Focus groups and survey pretesting are a vital part of this process. Table 1 illustrates a possible list of outcome attributes and levels for treatments for vasomotor symptoms (Johnson, Özdemir, Hauber, \& Kauf, 2007).

\section{Alternative Stated-Choice Formats}

Once attributes and levels are determined, they can be combined into treatment profiles that describe particular real or hypothetical treatments. Subjects

\section{Table 1. Treatment attributes and levels for vasomotor symptoms}

\begin{tabular}{|c|c|}
\hline $\begin{array}{l}\text { Treatment } \\
\text { Feature }\end{array}$ & Levels \\
\hline $\begin{array}{l}\text { Severity of } \\
\text { daytime hot } \\
\text { flashes }\end{array}$ & $\begin{array}{l}\text { - No daytime hot flashes } \\
\text { - Mild: a fleeting warm sensation with no } \\
\text { sweating that does not disrupt normal } \\
\text { daily activity } \\
\text { - Moderate: a warm sensation with } \\
\text { sweating that does not disrupt normal } \\
\text { daily activity } \\
\text { - Severe: a hot sensation with sweating } \\
\text { that can disrupt normal daily activity }\end{array}$ \\
\hline $\begin{array}{l}\text { Frequency of } \\
\text { daytime hot } \\
\text { flashes }\end{array}$ & $\begin{array}{l}\text { - None ( } 0 \text { times) during the daytime } \\
\text { - } 1-2 \text { times during the daytime } \\
\text { - } 3-6 \text { times during the daytime } \\
\text { - More than } 6 \text { times during the daytime }\end{array}$ \\
\hline $\begin{array}{l}\text { Frequency of } \\
\text { night sweats }\end{array}$ & $\begin{array}{l}\text { - None (0 times) per night } \\
\text { - } 1-3 \text { times per night } \\
\text { - } 4 \text { or more times per night }\end{array}$ \\
\hline $\begin{array}{l}\text { Duration of } \\
\text { hot flashes and } \\
\text { night sweats }\end{array}$ & $\begin{array}{l}\cdot 1 \text { year } \\
.2 \text { years } \\
.4 \text { years } \\
\text { - } 7 \text { or more years }\end{array}$ \\
\hline $\begin{array}{l}\text { Risk of heart } \\
\text { attack within } \\
10 \text { years }\end{array}$ & $\begin{array}{r}\cdot 38 / 1,000 \\
\cdot 50 / 1,000 \\
\cdot 65 / 1,000\end{array}$ \\
\hline
\end{tabular}


then evaluate these profiles in a series of SC tasks. Choosing an SC task format is an important step in developing an SC survey. Rating and discretechoice formats have been used in SC surveys. In a ratings approach, the subjects are presented with two treatment profiles and asked to indicate how strongly they prefer one to the other. Viscusi el al. (1991) used this approach to measure the value of avoiding an increase in the risk of contracting chronic bronchitis. Alternatively, discrete choice provides subjects with several different treatments simultaneously and simply asks them to identify the most preferred option in each choice set. Ryan and Hughes (1997) used the discrete-choice format to value women's preferences for miscarriage management. Johnson et al. (2000) used both rating and discrete-choice formats to value avoiding cardiovascular and respiratory symptoms.

Although the various SC task formats appear similar, studies have shown that subjects often use different simplifying decision rules for different formats. These decision strategies can produce somewhat different results for different SC formats. Therefore, the SC elicitation method should be context-specific, and study objectives should play a role in format selection (Huber, 1997). Figure 2 illustrates a rating task based on the vasomotor symptom treatment attributes presented in Table 1 (Johnson, Özdemir, Hauber, et al., 2007).

\section{Experimental Design}

The experimental design describes how many and which combinations of attribute levels must be evaluated by respondents to provide sufficient data for analysis. There are several ways to generate the experimental design. One is to simply evaluate all possible combinations of attribute levels. Such designs, called full-factorial experiments, typically are impractical for SC surveys because subjects' cognitive and time limitations do not allow consideration of a

\section{Figure 2. Example of a rating task for treatments for vasomotor symptoms}

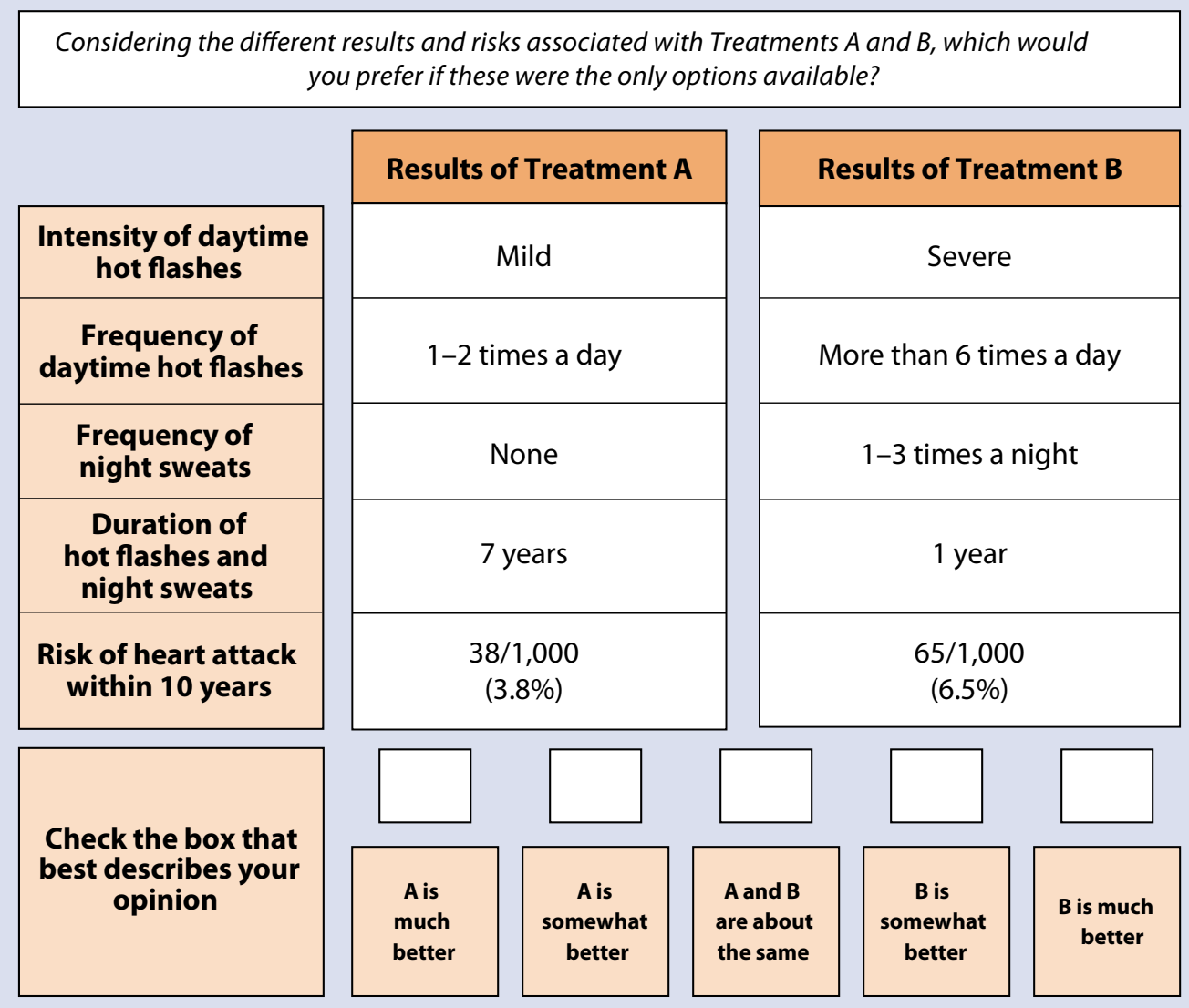


large number of profiles. For example, a full factorial design of the treatment attributes in Table 1 contains five attributes, three with four levels and two with three levels, resulting in $576(43 \times 32)$ possible health outcome profiles. In addition, subjects do not rate these options individually. Rather, subjects compare two or more options at a time. Considered in pairs, the number of possible pairwise combinations is 165,600 $([576 \times(576-1)] / 2)$, which obviously is impossible to evaluate.

Most current SC applications use an algorithm to reduce the number of comparisons to the smallest number necessary to efficiently quantify tradeoff preferences (Dey, 1985; Huber \& Zwerina, 1996; Kuhfeld, Tobias, \& Garratt, 1994). These "efficient" designs can be produced using an iterative computer algorithm (Kuhfeld, 2005; Zwerina, Huber, \& Kuhfeld, 2005).

\section{A Numerical Example}

The SC experimental design determines a sequence of profile evaluations for each subject. Using appropriate statistical analysis, the pattern of choices or ratings from questions like that shown in Figure 2 reveals the implicit importance of decision weights that subjects attach to each attribute level to evaluate alternatives. Our earlier example considered a set of five attributes that described vasomotor symptom treatment profiles. For simplicity, consider four 1-year symptom profiles and one side-effect risk $^{2}$ :

- Symptom severity

- Severe: Severe symptoms with more than 6 hot flushes during the day and 4 or more night sweats per night

- Moderate: Moderate symptoms with 3-6 hot flushes per day and 1-3 night sweats

- Mild: Mild symptoms with 1-2 hot flushes a day and $1-3$ night sweats

- None: No hot flushes or night sweats

- 10-year heart attack risk

- 40/1,000

- $65 / 1,000$

2 This example was adapted from Johnson, Özdemir, Hauber, et al. (2007).
In this case, the eight $(4 \times 2)$ alternatives in Table 2 describe all the possible profiles and represent the full-factorial design. In a rating format or twoalternative choice format, there are 28 possible profile pairs $([8 \times(8-1)] / 2)$. These could be divided into four blocks or survey versions so that each subject would evaluate seven pairs.

Table 2. Menopause treatment profiles

\begin{tabular}{clc} 
Profile & $\begin{array}{l}\text { Symptom } \\
\text { Severity }\end{array}$ & $\begin{array}{c}\text { 10-Year } \\
\text { Heart-Attack Risk }\end{array}$ \\
\hline 1 & Severe & $4.0 \%$ \\
\hline 2 & Severe & $6.5 \%$ \\
\hline 3 & Moderate & $4.0 \%$ \\
\hline 4 & Moderate & $6.5 \%$ \\
\hline 5 & Mild & $4.0 \%$ \\
\hline 6 & Mild & $6.5 \%$ \\
\hline 7 & None & $4.0 \%$ \\
\hline 8 & None & $6.5 \%$ \\
\hline
\end{tabular}

We can quantify the relative importance of each symptom profile and risk level from the answers to the tradeoff questions using statistical models. For example, we can use ordered probit or logit regression to analyze data from rating questions, and conditional logit regression to analyze data from discrete choice questions. Suppose an ordered-probit regression is used to estimate the parameters of the following utility model:

$$
\begin{aligned}
\mathrm{U}= & \beta_{\text {None }} \times \text { None }+\beta_{\text {Mild }} \times \text { Mild }+ \\
& \beta_{\text {Moderate }} \times \text { Moderate }+\beta_{\text {Risk } 4.0} \times \text { Risk }_{4.0}
\end{aligned}
$$

where $\mathrm{U}$ is the implicit SC utility for each profile. ${ }^{3}$ None, Mild, and Moderate are 0/1 dummy variables, and Severe is the omitted category. Risk 4.0 is a dummy variable for 4.0 percent, and 6.5 percent is the omitted category. The parameter estimates ( $\beta_{\text {None }}$, $\beta_{\text {Mild }}, \beta_{\text {Moderate, and }} \beta_{\text {Risk 4.0 }}$ ) measure marginal utility of changes in the treatment characteristics and are $\beta_{\text {None }}=0.5, \beta_{\text {Mild }}=0.40, \beta_{\text {Moderate }}=0.25$, and $\beta_{\text {Risk 4.0 }}=0.5$.

\footnotetext{
3 We use the term "SC utility" in the conventional economic sense, not the specialized sense of a standard-gamble or time-tradeoff utility that ranges between 0 for death and 1 for perfect health.
} 
The relative importance of each symptom profile and risk level is the estimated preference weight for that outcome. Omitted categories are assigned a weight of zero.

We can calculate the MAR for a treatment that improves symptoms from severe to moderate by dividing the SC utility change from better efficacy by the absolute change in SC utility for a unit change in risk. This formula calculates the risk increase that would leave utility unchanged if treatment efficacy increased.

As shown in Figure 1, MAR for each treatment is the increase in risk that would exactly offset the increase in SC utility from better efficacy. Because Severe is the omitted category with weight $=0$, the change in $U$ is just the estimated preference weight on the Moderate dummy variable. Offering a treatment that improves outcomes from Severe to Moderate increases patients' SC utility by 0.25 . According to the preference-weight estimates, each percentage point increase in risk changes patients' SC utility by $0.50 /(4.0-6.5)=-0.2$. Thus

$$
\frac{\mathrm{U}_{\text {moderate }}-\mathrm{U}_{\text {severe }}}{\left(\mathrm{U}_{4.0}-\mathrm{U}_{6.5}\right) / \Delta \text { Risk }}=\frac{0.25}{0.50 /(4.0-6.5)}=-1.25 \%
$$

If the treatment has a risk of $0.25 / 0.2=1.25$ percent, then the risk causes patients' utility to decrease by 0.25 and they are no better off than they would be without treatment. If treatment risk is more than 1.25 percent, then patients would be worse off with the treatment than without it. If treatment risk is less than 1.25 percent, then patients would be better off with the treatment than without it. ${ }^{4}$
Table 3 shows the difference in SC utility from more efficacious treatments that improve symptoms from Severe to each of the better categories. It also shows the MAR for each of these treatment improvements.

\begin{tabular}{lcc}
\hline $\begin{array}{l}\text { Table 3. Efficacy, satisfaction, and maximum } \\
\text { acceptable risk }\end{array}$ & $\begin{array}{c}\text { Change in } \\
\text { Stated Choice } \\
\text { Utility }\end{array}$ & $\begin{array}{c}\text { Maximum } \\
\text { Acceptable } \\
\text { Risk }\end{array}$ \\
\hline $\begin{array}{l}\text { Treatment } \\
\text { Efficacy (Symptom } \\
\text { Improvements) }\end{array}$ & 0.25 & $1.25 \%$ \\
\hline $\begin{array}{l}\text { Severe to } \\
\text { Moderate }\end{array}$ & 0.40 & $2.00 \%$ \\
\hline Severe to Mild & 0.50 & $2.50 \%$ \\
\hline Severe to None & & \\
\hline
\end{tabular}

Estimates from Johnson, Özdemir, Hauber, et al.s (2007) more complicated empirical application are plotted in Figure 3. (Note that the MAR estimates from these analyses are different from comparable estimates reported in Table 3 because they rely on a different regression model.) The results indicate that women are willing to accept a relatively large increase in heart attack risk to improve vasomotor symptoms from Severe to Moderate, but only a small increase in risk for an improvement from Moderate to Mild. The risk tolerance for an improvement from Mild to None falls somewhere in-between. The increase in heart attack risk originally reported in the Women's Health Initiative (WHI) study was about 0.4 percent (Rossouw et al., 2002). These results indicate that women are willing to accept risks above clinically observed levels only for significant treatment benefits.

Figure 3 also indicates that risk tolerance increases with the level of benefit offered. The dashed line suggests the shape of the benefit-risk tradeoff curve from Figure 1. If the horizontal axis were scaled with a continuous efficacy variable instead of categorical benefit levels, we could estimate the continuous dashed benefit-risk tradeoff curve directly.

\footnotetext{
4 Note that the number needed to harm, (Number Treated)/(Number Harmed), =1/Risk. Therefore, the maximum acceptable number needed to harm is $1 /$ MAR. For an improvement from severe to moderate symptoms, the maximum acceptable number needed to harm is thus $1 / 0.0125=80$.
} 
Figure 3. Maximum acceptable risk for vasomotor symptom treatment

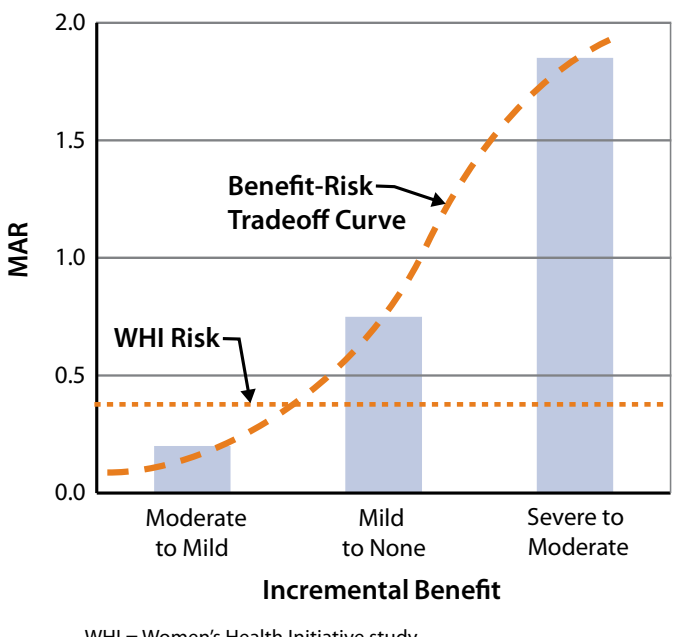

\section{Hypothetical Bias}

The most serious limitation of SC methods is that they employ judgments among hypothetical alternatives. Hypothetical choices do not have the same clinical, financial, and emotional consequences of actual choices. We can limit the problem of hypothetical bias by constructing choice tasks that mimic realistic clinical choices as closely as possible.

In addition, SC judgment tasks encourage subjects to explore their preferences for various attribute combinations. This process of explicitly trading off well-defined attributes encourages subject introspection despite the hypothetical context. Because each subject provides answers to multiple tradeoff questions, SC allows analysts to devise internal checks for attentiveness and consistency. Such tests can identify subjects who are insufficiently attentive to the tradeoff tasks or whose stated preferences do not conform to basic requirements of logic and consistency for other reasons. For example, a significant challenge in applying SC methods to evaluate benefit-risk tradeoff preferences is that some subjects may have difficulty understanding how risk is quantified. Devising effective ways of helping subjects conceptualize risk is very important in obtaining valid and reliable benefit-risk preference data.

\section{Using Stated Preferences to Inform Decisions Involving Benefit-Risk Tradeoffs}

Understanding patient and physician perceptions, preferences, and choices is important for reducing the incidence of adverse outcomes while making treatment benefits available to the largest possible number of patients. A carefully designed and skillfully implemented SC survey can produce valid and reliable estimates of patients' and other stakeholders' risk tolerance. These estimates may be useful, in conjunction with traditional forms of evidence, for informing product development decisions, licensing decisions, and clinical choices among alternative therapies.

Unlike product development and licensing decisions, clinical decisions involve individual patients who vary with respect to the likelihood they would experience given benefits or harms-and they also vary with respect to their risk tolerance. It is possible that particular patients may face a relatively large chance of experiencing a harmful side effect but have a high tolerance for risk, while other patients have a very small chance of experiencing a harmful side effect but are intolerant of even small treatment-related risks. SC data can help identify the factors that influence patients' risk tolerance. This information may help physicians and patients identify treatments that are most consistent with both their health condition and their attitudes toward bearing risk.

When attributes and levels are carefully selected, SC data can provide useful answers to a variety of "what if" questions. For example, understanding what kinds of side-effect risks are of greatest concern to patients may help identify appropriate strategies for modifying drug formulations, designing more useful labels, or helping physicians communicate more effectively with their patients. 


\section{References}

Brown, D. S., Finkelstein, E. A., Brown, D. R., Buchner, D. M., \& Johnson, F. R. (2009). Estimating older adults' preferences for walking programs via conjoint analysis. American Journal of Preventive Medicine, 36(3), 201-207.e4.

Bryan, S., Buxton, M., Sheldon, R., \& Grant, A. 1998. (1998). Magnetic resonance imaging for the investigation of knee injuries: An investigation of preferences. Health Economics, 7, 595-603.

Dey, A. 1985. (1985). Orthogonal fractional factorial designs. New York: Halstead Press.

Hauber, A. B., Mohamed, A. F., Johnson, F. R., Meddis, D., Wagner, S., \& O'Dowd, L. (2009). Quantifying asthma patient preferences for onset of effect of combination inhaled corticosteroids and long-acting beta2-agonist maintenance medications. Allergy and Asthma Proceedings, 30(2): 139-147.

Hensher, D. A., Rose, J. M., \& Greene, W. H. (2005). Applied choice analysis: A Primer. New York: Cambridge University Press.

Huber, J. (1997). What we have learned from 20 years of conjoint research: When to use self-explicated, graded pairs, full profiles or choice experiments. Retrieved August 31, 2009, from Sawtooth Software Web site: http://www.sawtoothsoftware.com/ download/techpap/whatlrnd.pdf

Huber, J., \& Zwerina, K. B. (1996). The importance of utility balance in efficient choice designs. Journal of Marketing Research, 33, 307-317.

Institute of Medicine. (2006). The future of drug safety: Promoting and protecting the health of the public. Washington, DC: The National Academies Press.

Johnson, F. R., \& Desvousges, W. H. (1997). Estimating stated preferences with rated-pair data: Environmental, health, and employment effects of energy programs. Journal of Environmental Economics and Management, 34, 79-99.

Johnson, F. R., Banzhaf, M. R., \& Desvousges, W. H. (2000). Willingness to pay for improved respiratory and cardiovascular health: A multiple-format stated-preference approach. Health Economics, 9, 295-317.
Johnson, F. R., Desvousges, W. H., Ruby M. C., Stieb, D., \& De Civita, P. (1998). Eliciting stated preferences: An application to willingness to pay for longevity. Medical Decision Making, 18(Suppl), S57-S67.

Johnson, F. R., Manjunath, R., Mansfield, C. A., Clayton, L. J., Hoerger, T. J., \& Zhang, P. (2006). High-risk individuals' willingness to pay for diabetes risk-reduction programs. Diabetes Care, 29(6), 1351-1356.

Johnson, F. R., Özdemir, S., Hauber, A. B., \& Kauf, K. L. (2007). Women's stated willingness to accept perceived risks for vasomotor symptom relief. Journal of Women's Health, 16(7), 1028-1040.

Johnson, F. R., Özdemir, S., Mansfield, C., Hass, S., Miller, D., \& Siegel, C. (2007). Crohn's disease patients' risk-benefit preferences: Serious adverse event risks versus treatment efficacy. Gastroenterology, 133(3), 769-779.

Johnson, F. R., Van Houtven, G., Özdemir, S., Hass, S., White, J., \& Francis, G. (2009). Multiple sclerosis patients' benefit-risk preferences: Serious adverse event risks versus treatment efficacy. Journal of Neurology, 256:554-562.

Kuhfeld, W. F. (2005). Marketing research methods in SAS. SAS Technical Paper TS-722. Retrieved January 19, 2009, from SAS Institute Web site: http://support.sas.com/techsup/technote/ts722.pdf

Kuhfeld, W. F., Tobias, R. D., \& Garratt, M. (1994). Efficient experimental design with marketing research applications. Journal of Marketing Research, 31, 545-557.

Mansfield, C., Johnson, F. R., \& Van Houtven, G. (2006). The missing piece: Valuing averting behavior for children's ozone exposures. Resource and Energy Economics, 28(3), 215-228.

Mansfield, C., Phaneuf, D., Johnson, F. R., Yang, J. C., \& Beach, R. (2008). Preferences for public lands management under competing uses: The case of Yellowstone National Park. Land Economics, 84, 284-307. 
Marshall, D., Johnson, F. R., Kulin, N., Özdemir, S., Walsh, J., Marshall, J., van Bebber, S., \& Phillips, K. A. (2009). How do physician assessments of patient preferences for colorectal cancer screening tests differ from actual preferences? A comparison in Canada and the United States using a stated-choice survey. Health Economics, doi: 10.1002/hec.1437.

Roe, B., Irwin, E. G., \& Morrow-Jones, H. A. (2004). The effects of farmland, farmland preservation, and other neighborhood amenities on housing values and residential growth. Land Economics, 80(1), 55-75.

Rossouw, J.E., Anderson, G. L., Prentice, R. L., LaCroix, A. Z., Kooperberg, C., Stefanick, M. L., Jackson, R. D., Beresford, S. A. A., Howard, B. V., Johnson, K. C., Morley Kotchen, J., \& Ockene, J. (2002). Risks and benefits of estrogen plus progestin in healthy postmenopausal women: Principal results from the Women's Health Initiative randomized controlled trial. Journal of the American Medical Association, 288, 321-333.
Ryan, M., \& Hughes, J. (1997). Using conjoint analysis to assess women's preferences for miscarriage management. Health Economics, 6, 261-273.

Viscusi, W. K., Magat, W. A., \& Huber J. (1991). Pricing environmental health risks: Survey assessments of risk-risk and risk-dollar trade-offs for chronic bronchitis. Journal of Environmental Economics and Management, 21, 32-51.

Wittink, D. R., \& Cattin, P. (1989). Commercial use of conjoint analysis: An update. Journal of Marketing, 53, 91-96.

Yoo, S.-H., Kwak, S.-J., \& Lee, J.-S. (2008). Using a choice experiment to measure the environmental costs of air pollution impacts in Seoul. Journal of Environmental Management, 86(1), 308-318.

Zwerina, K., Huber, J., \& Kuhfeld, W. F. (2005). A general method for constructing efficient choice designs. SAS Technical Document TS-722E. Retrieved January 19, 2009, from SAS Institute Web site: http://support.sas.com/techsup/technote/ ts722e.pdf 

RTI International is an independent, nonprofit research organization dedicated to improving the human condition by turning knowledge into practice. RTI offers innovative research and technical solutions to governments and businesses worldwide in the areas of health and pharmaceuticals, education and training, surveys and statistics, advanced technology, international development, economic and social policy, energy and the environment, and laboratory and chemistry services.

The RTI Press complements traditional publication outlets by providing another way for RTI researchers to disseminate the knowledge they generate. This PDF document is offered as a public service of RTI International. More information about RTI Press can be found at www.rti.org/rtipress. 